\section{SURGERY OF MODERN WARFARE 3rd Edition}

Edited by Hamilton Bailey. In six parts. E. \& S. Livingstone, Ltd., Edinburgh. Parts IV, V and VI. I5s. each part.

A review of Parts I, II and III has already appeared, and this review deals with the remaining parts now available. These volumes fully maintain the high standard set by the earlier ones.

In Part IV, in the chapter on wounds of bone, one hoped to find some details of the recent work on Caisson disease - there was only a passing reference to bone changes in the description of this disease given in Part $I$. The table given on p. 509, setting out the factors which influence the decision to amputate, should be of considerable value to the surgeon inexperienced in war surgery and the after-results of amputation. The articles by the Editor are, as one would expect, models of clear exposition.

Seddon's article on nerve injuries is the most recent and authoritative work on this subject, and carries the work of the last war, which still stands the test of time, up to the latest experience of this war. One of the difficulties of any work dealing with a rapidly expanding subject is that advances must occur while the article is being printed, hence the need for new editions. Seddon refers to the fibrin suture of nerves, but this technique is still somewhat experimental, and perhaps by the next edition it will be either established-or dropped.

The article on the management of the bladder will have a sobering effect on those who hope to keep a bladder clean by an indwelling catheter with tidal drainage or other special devices.

One wonders why the simple technique of trocar and cannula, and the introduction of a de Pesser catheter through the cannula, is not more used. The writer of this review has used it since he learnt it twenty years ago in Graham Simpson's clinic, Sheffield, where it was the routine procedure, and he has never seen any ill effect; it is simple, quick, and gives a water-tight joint. Some urologists decry this method, and prefer to make almost a major operation of suprapubic catheterisation. One is tempted to quote the joke in Punch, of two middle-aged men looking through a ballroom door-one says "a foul dance, this Charleston; don't you think so?" and the other replies, "Yes-I can't do it either!"

The article on plastic surgery, by Kilner, gives a good idea of what can be achieved, and it sets out not to create a plastic surgeon by detailed instruction, but (I) to outline treatment, which in many cases will be all that is required, (2) to ensure in more severe injuries that the first treatment shall be preparatory for a later reconstruction, and (3) to indicate briefly the main types of reconstruction. One must approve of these aims. The work is written for those who have to deal with all types of wounds, and much of the final result will depend upon the first treatment.

In Part $\mathrm{V}$, the names of Dott, Negus, Tudor Edwards, and Sir John Fraser, will show the standard of the articles.

In a work that has reached the third edition one would not expect to find major errors, and criticism is therefore somewhat trivial. In dealing with the closure of a skull defect by split ribs nothing is said as to whether it matters if the cancellous surface of the rib faces inwards or outwards. The illustration appears to indicate that alternate ribs face opposite directions.

The chapter on wounds of the thorax has been written in a very practical manner, and deals with such wounds in the forward area-(b) during evacuation, and $(c)$ in the hospital.
The chapters on intra-abdominal surgery are perhaps the least up to date, being almost entirely founded on experience in the last war; however, Ogilvie in a recent article (Surg., Gyn., \& Obstets., Mar. 1944) vol. 78, 225.238) states that there has been little change in treatment of this region, with the exception of the large bowel. of

In Part VI, one is very impressed with the article on large intestine, by Gordon Taylor, and by the up to dafe knowledge and information contained therein.

In dealing with post-operative complications, one wouffd like to have a little more information about the passipg of a Miller Abbott tube. It always seems a little incredible, and rather like the Indian rope trick, and I am still trying to meet a man who has really passed a Miller Abbott tube into the small intestine.

A good deal of Part VI deals with administration and organisation, and will prove of topical interest.

The final chapter is in the nature of a "stop press and includes among other matters an account of intresternal and osteomedullary infusions. One wonders ho often these will be required, and the risk of really serioins consequences of any failure of aseptic technique is sufficient to make one very cautious in accepting such method for general use.

Hamilton Bailey's Surgery of Modern Warfare is one Gef those rare epoch-making events, an international classic. Long after the war, it will form the basis of much surgical treatment, though its gems may appear in nefr settings. It is to be hoped that in future editions, younger men with recent experience may be amongst the contributors. That a work of such scope, compiled by close on eighty writers, shows such a high degree of co-or $\overline{\text { f }}-$ nation, lack of overlapping or gaps, and absence of comtradictions, is a high tribute to the skill and industry of the Editor.

Hamilton Bailey has every reason to be proud of work, and all of us who deal with casualties have reason to be grateful to him for the help he has given us.

One can certainly say that this is a book that surgeon dealing with either military or civil casualtiês should be without.

\section{CATECHISM SERIES. ANATOMY (UPPER EXTREMITY) PART I 6th Edition}

By C. R. Whittaker. E. \& S. Livingstone, Edinburg 1944. Price Is. 6d.

This new enlarged sixth edition of Part I of twe catechism series covered the upper extremity, and wïl be found as valuable a friend to 2nd M.B. and "Primary" candidates as its well-known predecessors.

\section{A HANDBOOK OF FIRST AID AND BANDAGING}

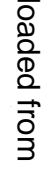

By Arthur D. Belilios, M.B., B.S., D.P.H., Desmond MULVANY, M.B., B.S., F.R.C.P.I., F.R.C.S., a KATHERINe F." ARMSTRONG, S.R.N., S.C.M. 2met Edition. Baillière, Tindall \& Cox, London. 194 , Price 4s. 6d.

This is the second edition of a handbook designed $\stackrel{N}{\mathscr{R}}$ give "a complete training in first aid, yet written simply that it can be as readily understood by the beginner as by the advanced student." Examination of it shows that the learned authors have succeeded admi ably, and what with the wealth of illustration the book would be a first-rate introduction for a medical studesit at the start of his course, besides teaching him mant useful things in practice that are apt to be overlooked of 
bis later studies. The matter and its arrangement are excellent, and the directions are clear and precise. The scope of the work is wide and up-to-date, there being chapters on Psychological Ailments, Industrial Poisons, First Aid in Maternity Cases and in Chemical Warfare, and Preparation for the Reception of an Accident.

The first edition (issued in I94I) had three reprints: this one should have many more.

\section{PSYCHOLOGICAL MEDICINE:}

\section{A short introductory to Psychiatry with an Appendix War-time Psychiatry}

By Desmond Curran, M.B., F.R.C.P., D.P.M., and ERIC GutTManN, M.D., L.R.C.P.(Ed.). E. \& S. Livingstone. 1943. Price ros. 6d.

The study of Psychiatry is beginning to find its rightful place in the proposed curricula of the Medical Colleges. The days of the haphazard "mad or not mad" by the many, and the over-enthusiastic pursuit of complexes and the splitting of hairs and personalities by the few, are numbered. There is dawning a more rational approach to mental disorder. A symptom of this new era is perhaps the appearance of this very useful book by Curran and Guttmann. There is nothing revolutionary in the presentation of the subject-matter, but there is much common sense.

There are, however, far too many terms which the student and practitioner will find difficult to remember, and his reading will thereby lose much of its continuity. One looks forward to the day not long distant when psychiatry will be presented in as "basic" and intelligible a language as possible. A glossary of terms at the end of this book would be invaluable for the beginner. There are minor blemishes in a book that is refreshingly well written and clear. Anyone reading psychiatry for the first time will find this introduction adequate, and it will stimulate him to read further afield in the directions indicated in the very well selected bibliography. The brief sections on treatment are clear, and a busy general practitioner will find the dosages suggested of the commoner and newer drugs helpful. The illustrations are very good, but the photograph facing page 66 is out of taste and unnecessary. The appendix on War-time Psychiatry follows the same sound lines as the remainder of the book. The comforting thought that the more acute disorders arising from external stress are easier to deal with will not only appeal to Service men, but should also invite them to consider carefully the aetiology of the more prolonged and serious functional states the products of internal conflict and external stress.

This new book is strongly recommended as a sound beginning to the serious study of Psychiatry.

\section{TEXTBOOK OF MEDICAL TREATMENT}

By various Authors: edited by Professors D. M. DusLOP, L. S. P. DAVIDSON, and J. W. MCNEE, with a foreword by the late Professor A. J. ClARK. 3rd Edition. E. \& S. Livingstone, Edinburgh. 1944. 30s. net.

This successful work of 1,184 pages and 34 pages of Index, first issued in 1939, and now with two editions and two reprints to its credit, has been thoroughly revised and in part rewritten for this third edition, in view of the rapid advances in medical therapeutics. To meet the developments in sulphonamide chemotberapy, and avoid frequent repetitions under many headings, a new section has been devoted to these drugs, in which their dosage, action, and toxic effects are dealt with. Diseases of the Skin, Tropics, and Industry, and Children are all included, and also Psychotheraphy in General Practice. \& There is also a very valuable chapter on Technical Pro- $c$ cedures and Oxygen Therapy.

The exposition of Medical Treatment is accomplished in twenty-three sections contributed by twenty-nine authorities, and is thoroughly detailed and explicit in regard to general management, nursing, diet, rest, sleep, relief of symptoms, special treatments, drugs, convalescence, after care, and technical procedures. Prophylaxis, maintenance and pre-operative treatments, blood transfusion, the various injections, infusions, punctures, etc., are all described, and detailed diets are given for the requisite conditions.

A careful study of this excellent book will show what a splendid and competent guide it can and will be to the student and practitioner of medicine amid the multiplicity of methods and measures and newer drugs in all their potency. It is refreshing to read a book where the conclusions are set out with such directness and candour, and the carrying-out of them so clearly outlined, and the whole so seasoned and informed with the authors' welltried experience. An outstanding book.

\section{THE HOSPITAL CARE OF THE SURGICAL PATIENT}

By George Crile, Jr., M.D., and Franklin L. Shirely, Jr., M.D. Chas. C. Thomas, Springfield, U.S.A.; Baillière, Tindall \& Cox, London. r943. Price r4s.

This book is written primarily for the American interm but its conterits may be read by British House Surgeon with equal advantage.

The first section is devoted to "physiological principles related to the care of the Surgical Patient," and contains an excellent summary of water balance, chloride balance, and the relative values of saline, plasma, blood, etc. While the various dangers of intravenous therapy are presented in a rational manner, many oft-repeated theories and dangers are suitably debunked, and it is refreshing in these times to read in print that fluid is absorbed via the intestinal tract as well as the veins. This section might be read by all surgeons with advantage.

The section on "management of surgical complications" contains simple and sound advice upon such subjects as faecal impaction, wound disruption, pulmonary complications, phlebitis, parotitis, etc., to quote only a few.

On page 25, under "overdistended bladder," appears the sentence, "If each patient who has been unable to void is catheterized at least once after he first voids, the presence of large amounts of residual urine will not be overlooked." Untortunately no clear advice is now given $\supsetneq$ as to what to do if there is residual urine.

Otherwise this section is admirably presented.

Section III describes the technique of common Hospital $D$ procedures such as lumbar puncture, blood transfusion, 을 catheterization, gastric lavage, and the use of the Miller- $\bar{N}$ Abbott tube, tracheotomy, etc.

A very good chapter is devoted to the "relationships of the House Officer" in regard to patients, nursing staff and N chiefs. Many indifferent testimonials could be avoided by reading this chapter.

At the end of the book are a few pages of Drugs, Doses and Data, and a short bibliography.

Having made allowances fer American spelling and the sixteen-ounce pint, the reviewer found that the excellent $\stackrel{\mathscr{S}}{+}$ advice contained in this book and its simple style made it a pleasure to read. 